\title{
Fabrication and Characterization of Zinc Oxide Nanoparticle-treated Kenaf Polymer Composites for Weather Resistance Based on a Solar UV Radiation
}

\author{
Mohammed Mohammed, ${ }^{\mathrm{a}}$ Rozyanty Rahman, ${ }^{\mathrm{a}}$ Aeshah M. Mohammed, ${ }^{\mathrm{b}}$ \\ Azlin F. Osman, ${ }^{\mathrm{a}}$ Tijjani Adam, ${ }^{\mathrm{c}}$ Omar S. Dahham, ${ }^{\mathrm{c}}$ Uda Hashim, ${ }^{\mathrm{d}}$ Nik Z. Noriman, ${ }^{\mathrm{c}}$ and \\ Bashir O. Betar ${ }^{\mathrm{e}}$
}

\begin{abstract}
Polyester/kenaf composites reinforced with zinc oxide nanoparticles (ZnO NPs) were fabricated. The nanoparticle treatment had a noticeable effect on the mechanical properties of the composites. Kenaf treatments with five different concentrations $1 \%, 2 \%, 3 \%, 4 \%$, and $5 \%$ were performed. The mechanical analysis showed an increased flexural strength stability and break elongation in the functionalized ZnO NPstreated kenaf polyester resin composites. The polymer nanocomposites with $2 \% \mathrm{ZnO}$ NPs had stable mechanical properties with moderate elastic properties compared with the remaining ZnO NPs systems. The mechanical properties of the composites that contained different layers of kenaf mat demonstrated positive influence on the polymer nanocomposites. The material increased in stiffness with an increase in layers from 1 to 5 . The results of weathering confirmed the stability of the polymer nanocomposites with increased stability. The $2 \%$ nanoparticle coating with a 5-layer kenaf layer revealed no remarkable changes in the mechanical degradation throughout the 6-month weathering period. The results of the mechanical properties tests suggested that a $2 \%$ ZnO NPs concentration with five kenaf layers had the highest moisture resistance, thus; the $\mathrm{ZnO} N P s$ acted as a water repellent agent.
\end{abstract}

Keywords: Fabrication; Zinc oxide; Nanoparticles; Kenaf; Radiation

Contact information: a: Center of Excellence Geopolymer and Green Technology, School of Materials Engineering, Universiti Malaysia Perlis, 01007, P.O. Box 77, D/A Pejabat Pos Besar, Kangar, Perlis, Malaysia; $b$ : University of Bagdad College of Education for Pure Science Ibn-Alhaitham; c: Faculty of Technology, Universiti Malaysia Perlis, Kampus Uniciti Alam Sg. Chuchuh, 02100 Padang Besar (U), Perlis, Malaysia; d: Institute of Nano Electronic Engineering, Universiti Malaysia Perlis, 01000 Kangar, Perlis, Malaysia; e: Research Center (NANOCAT),University of Malaya, Kuala Lumpur 50603, Malaysia; *Corresponding author: tijjani@unimap.edu.my

\section{INTRODUCTION}

Nano-based materials have shown very different behaviour from their bulk counterparts (Guo et al. 2008; Cierech et al. 2016, Mohammed et al. 2017a,b). Compared to macroscopic materials, nanoscale materials have been found to possess distinct and unique physical, chemical, and optical properties due to their small size and high surface to volume ratio (Guo et al. 2008; Cierech et al. 2016; Mohammed et al. 2017a,b). These unique potentials have provoked substantial interest in many different applications, such as device sensors and nanomaterials (Kabir et al. 2013; El-Sabbagh 2014; Tawakkal et al. 2014; Karger-Kocsis et al. 2015; Lai et al. 2016). Both constitute great potential, especially the nanomaterials, due to their unique physicochemical properties (Mou et al. 2016). The materials have been used in a wide range of applications, such as a filler in 
polymers to improve the mechanical, electric, electronic, and optical properties (Arrakhiz et al. 2013a; Venkateshwaran et al. 2013; Shah 2014; Shukor et al. 2014; Zaikikhani et al. 2014). The polymer reinforced or filled nanomaterials have attracted much interest by a wider community of scientists due to their potential application for lighter devices, compatibility with homogeneity, ease of processing, and their cost-effective re-process ability (Guo et al. 2008; Cierech et al. 2016; Mohammed et al. 2017a,b). The nanoparticles have an engineerable atomic profile that could be used to manipulate physical and chemical properties (Kabir et al. 2013; El-Sabbagh 2014; Tawakkal et al. 2014; Karger-Kocsis et al. 2015; Lai et al. 2016). The natural fibre composites that are exposed outdoors to direct sunlight are subjected to radiation, which breaks the covalent bonds in organic polymers, causing yellowing, colour fading, weight loss, surface roughening, mechanical property deterioration, and embrittlement (Venkateshwaran et al. 2013; Shukor et al. 2014; Shah 2014; Zaikikhani et al. 2014). Increased reduction occurs in wetter conditions because photodegradation causes changes in all scales of polymer dimensions, including the monomer unit (oxidation), the chain (crosslinking or chain scission), the morphology (breakdown of the molecules and crystal), and on the macroscopic scale (Kabir et al. 2013; El-Sabbagh 2014; Tawakkal et al. 2014; KargerKocsis et al. 2015; Lai et al. 2016). The ultraviolet (UV) radiation absorbed by the polymers modifies the chemical structure, providing a molecular chain scission and/or a chain crosslinking (Arrakhiz et al. 2013a; Reddy et al. 2013; Al-Oqla and Sapuan 2014; Bing et al. 2014; Salleh et al. 2014). The degradation processes via weathering, which includes photoradiation, thermal degradation, photo-oxidation, and hydrolysis, results in changes in the chemical, physical, and mechanical properties of materials. Photodegradation of the polymers via photo-oxidation is promoted by UV irradiation (Arrakhiz et al. 2013b; Bing et al. 2014). Therefore, a suitable surface treatment is needed to counter this problem.

The poor adhesion between fibres and the fact that the polymer matrix generates void spaces around the fibres in natural fibres composites, which leads to a higher water uptake, are equal causes of the early material degradation (Venkateshwaran et al. 2013; Shukor et al. 2014). Several studies have been proposed in fibre modification, and among them is fibre modification via alkalization, which can reduce the moisture absorption (Cierech et al. 2016; Mohammed et al. 2017a,b). Potassium hydroxide $(\mathrm{KOH})$ and sodium hydroxide $(\mathrm{NaOH})$ are commonly used to decrease the hydrogen bonding capacity of cellulose and eliminate open hydroxyl groups that tend to bond with water molecules. Unfortunately, this approach has some limitations due to lower overall strength properties and lower interfacial adhesion (Deka et al. 2013; Xia et al. 2016). Another approach is modification via discharge treatment, such as low-temperature plasma, sputtering, and corona discharge, which changes the functional properties of natural fibres (El-Sabbagh 2014; Lai et al. 2016). Unfortunately, the etching influences mainly physical changes, such as surface voids, which leads to a decrease in mechanical adhesion (Cierech et al. 2016; Mohammed et al. 2017a,b). Another common treatment is via alkaline treatment, which was widely used to modify the surface of natural fibres. Thereby, the alkaline treatment affects the degree of polymerization (DP), the cellulosic fibril, and the removal of hemicellulosic and lignin compounds (Cierech et al. 2016; Mohammed et al. 2017a,b). Moreover, the mechanical properties are enhanced by increasing the surface roughness and increasing the quantity of cellulose molecules that are located on the surface of the fibre and this treatment removed the lignin and hemicellulose. It has been reported that their removal results in less rigid mechanical 
properties (Deka et al. 2013; Xia et al. 2016); therefore, an alternative approach is necessary.

Natural materials such as kenaf in composites are not able to stand environmental conditions because they have excessive wettability (Mohammed et al. 2017a,b). Natural materials are incompatible with most polymeric matrices and exhibit high moisture absorption. They easily form voids within composites, which can reduce the mechanical properties of a composite (Mohammed et al. 2017a,b). With these problems in mind, it is found that incorporation of $\mathrm{ZnO}$ nano material will improve the mechanical properties.

This study proposed a zinc oxide nanoparticle ( $\mathrm{ZnO} \mathrm{NP}$ ), which was found to possess high photocatalytic efficiency among all inorganic photocatalytic materials, and is more biocompatible with natural materials. Moreover, due to nanomaterials' surface to volume ratio, the interfacial forces, such as the Van der Waals force, electrostatic force, and capillary forces near the nanoparticle dominate the adhesion process (Deka et al. 2013; Alavudeen et al. 2015; Bakar et al. 2015; Xia et al. 2016; Yusoff et al. 2016). The polyester resin structural polymer matrix was chosen because the unsaturated polyester resin provided a network structure with resistance to the moisture and chemicals with reasonable mechanical properties. Therefore, with these potential properties, the ease of processing, and the $\mathrm{ZnO}$ NPs, polyester, and kenaf natural fibres were chosen for the fabrication and characterization of zinc oxide nanoparticle-treated kenaf polymer composites for weather resistance based on solar radiation assisted moisture repellent.

\section{EXPERIMENTAL}

\section{Materials}

Kenaf fibre was obtained from Rahamatullah Sdn. Bhd (Kedah, Malaysia). The kenaf was in mat form and used without any further treatment. A standard unsaturated polyesters resin was supplied by Castmesch Technologies Sdn. Bhd. (Perak, Malaysia). Methyl ethyl ketone peroxide (MEKP; solution in dimethyl phthalate) was obtained from Kaumjung Akzo Nobel Peroxide Ltd. (Tianjin, China) by the trade name Butanox M60. Nano-zinc oxide ( $\mathrm{ZnO}<100 \mathrm{~nm}$ particle size) was purchased from Sigma-Aldrich (M) Sdn. Bhd. (Kuala Lumpur, Malaysia). The nano-zinc oxide (nano-ZnO), unsaturated polyester (UP), and MEKP UP had a hazy pinkish colour with a gel time of 18 min to 23 min at $25{ }^{\circ} \mathrm{C}$ with $2 \%$ MEKP. The density of the UP was $1.4 \mathrm{~g} / \mathrm{cm}^{3}$ with a specific gravity of $1.12 \mathrm{~g} / \mathrm{cm}^{3}$ and a volumetric shrinkage of $8 \%$. The MEKP was colourless in appearance with a density of $1.15 \mathrm{~g} / \mathrm{cm}^{3}$ with a melting point of $-8{ }^{\circ} \mathrm{C}$ and a boiling point of $109^{\circ} \mathrm{C}$. The fabrication and testing consist of 7 major steps.

The initial step was the kenaf fibre mat being cut into $20 \mathrm{~cm} \times 20 \mathrm{~cm}$ dimensions. Different concentrations of the nano-ZnO were applied, i.e. 0, 1, 2, 3, 4 and $5 \mathrm{wt} \%$. For the high-speed mixing, a Ragogna mixer custom built for FPInnovations by Custom Machinery Ltd. (Ontario, Canada) with a speed up to 5,000 rpm was employed. To avoid destabilization of the emulsion, a moderate mixing speed (up to 2,500 rpm) at room temperature was used and a good dispersion was obtained with powder. This was followed by submerging the prepared kenaf into the prepared nanoparticle in water, following the process according to the procedure in Mohammed et al. (2017a). To avoid sedimentation of the nanoparticles, the kenaf fibre was immediately submerged in the suspension containing the nano- $\mathrm{ZnO}$ for $60 \mathrm{~min}$ at $60{ }^{\circ} \mathrm{C}$ and in a vacuum of $600 \mathrm{~mm} \mathrm{Hg}$ to increase penetration of the solution. The treated kenaf fibres were then washed with 
distilled water to remove the excess chemicals. The treated kenaf fibre layers were placed in a conventional oven to dry at $80{ }^{\circ} \mathrm{C}$ overnight. This was followed by compressing the untreated and treated kenaf fibres with nano- $\mathrm{ZnO}$ using a universal testing machine (Instron 5569; Instron, Norwood, MA, USA) at $90{ }^{\circ} \mathrm{C}$. Prior to putting the fibres into the mold, the resin was placed via a hand lay-up method at the bottom of the kenaf; then the kenaf was placed inside the mold.

Different loadings of untreated and treated kenaf fibres with the nano- $\mathrm{ZnO}$ were applied, i.e., $10 \mathrm{wt} \%, 20 \mathrm{wt} \%, 30 \mathrm{wt} \%$, and $40 \mathrm{wt} \%$. The resin was impregnated into the untreated and treated kenaf via a hand lay-up method and 2\% of MEKP was added as a hardener for all of the samples. This process was followed by resin impregnation, which was divided into two stages: (1) fabrication of the layer of untreated kenaf where it was impregnated into 1, 2, 3, and 4 layers to make an untreated kenaf unsaturated polyester composites as a control composite; and (2) fabrication of the $\mathrm{ZnO}$ NP-treated kenaf where the resin was impregnated into 1, 2, 3, and 4 layers of kenaf to make a $\mathrm{ZnO} \mathrm{NP}$ treated kenaf unsaturated polyester composite. Next, the composites were compressed for $10 \mathrm{~min}$ without heating. The prepared composite was measured and cut to $2.5 \mathrm{~cm} \times 20$ $\mathrm{cm}$. The authors compared the untreated kenaf unsaturated polyester composite at room temperature with the $\mathrm{ZnO}$ NP-treated kenaf unsaturated polyester composite.

The weathering study was performed in accordance to "ASTM D1435-13, "Standard Practice for outdoor weathering of plastics", ASTM International, West Conshohocken, PA, 2013". The specimens were prepared and exposed to weather for 6 months in intervals of 2 weeks and after each interval, the samples were tested as shown in the formulation Table 1.

Table 1. Formations Evaluated

\begin{tabular}{|c|c|c|c|}
\hline System & $\begin{array}{l}\text { Kenaf } \\
\text { layers }\end{array}$ & Treatment & Weathering (months) \\
\hline \multirow[t]{4}{*}{ System 1} & \multirow[t]{4}{*}{ O Layers } & $1 \%$ & $1,2,3,4,5,6$ \\
\hline & & $3 \%$ & $1,2,3,4,5,6$ \\
\hline & & $4 \%$ & $1,2,3,4,5,6$ \\
\hline & & $5 \%$ & $1,2,3,4,5,6$ \\
\hline \multirow[t]{5}{*}{ System 2} & \multirow[t]{5}{*}{1 Layer } & $1 \%$ & $1,2,3,4,5,6$ \\
\hline & & $2 \%$ & $1,2,3,4,5,6$ \\
\hline & & $3 \%$ & $1,2,3,4,5,6$ \\
\hline & & $4 \%$ & $1,2,3,4,5,6$ \\
\hline & & $5 \%$ & $1,2,3,4,5,6$ \\
\hline \multirow[t]{5}{*}{ System 3} & \multirow[t]{5}{*}{2 Layers } & $1 \%$ & $1,2,3,4,5,6$ \\
\hline & & $2 \%$ & $1,2,3,4,5,6$ \\
\hline & & $3 \%$ & $1,2,3,4,5,6$ \\
\hline & & $4 \%$ & $1,2,3,4,5,6$ \\
\hline & & $5 \%$ & $1,2,3,4,5,6$ \\
\hline \multirow[t]{5}{*}{ System 4} & \multirow[t]{5}{*}{3 Layers } & $1 \%$ & $1,2,3,4,5,6$ \\
\hline & & $2 \%$ & $1,2,3,4,5,6$ \\
\hline & & $3 \%$ & $1,2,3,4,5,6$ \\
\hline & & $4 \%$ & $1,2,3,4,5,6$ \\
\hline & & $5 \%$ & $1,2,3,4,5,6$ \\
\hline \multirow[t]{5}{*}{ System 5} & \multirow[t]{5}{*}{4 Layers } & $1 \%$ & $1,2,3,4,5,6$ \\
\hline & & $2 \%$ & $1,2,3,4,5,6$ \\
\hline & & $3 \%$ & $1,2,3,4,5,6$ \\
\hline & & $4 \%$ & $1,2,3,4,5,6$ \\
\hline & & $5 \%$ & $1,2,3,4,5,6$ \\
\hline
\end{tabular}


Finally, the physical characterization was conducted with a scanning electron microscope (JSM6400; JEOL Ltd., Tokyo, Japan) and mechanical testing for the tensile and flexural tests were performed in the Kubang Gajah Laboratory, Universiti Malaysia Perlis, via a universal testing machine (Instron 5569; Instron, Norwood, MA, USA) based on "ASTM D638-14, "Standard Test Method for Tensile Properties of Plastics", ASTM International, West Conshohocken, PA, 2014".

\section{Methods}

Next, the untreated and treated kenaf fibres with nano- $\mathrm{ZnO}$ were compressed using a universal testing machine (Instron 5569; Instron, Norwood, MA, USA) at $90{ }^{\circ} \mathrm{C}$. Prior to putting the fibres into the mold, the resin was placed via a hand lay-up method at the bottom of the kenaf; then the kenaf was placed inside the mold. Different loadings of untreated and treated kenaf fibres with the nano- $\mathrm{ZnO}$ were applied, i.e., $10 \mathrm{wt} \%, 20 \mathrm{wt} \%$, $30 \mathrm{wt} \%$, and $40 \mathrm{wt} \%$. The resin was impregnated into the untreated and treated kenaf via a hand lay-up method, and $2 \%$ of MEKP was added as a hardener for all of the samples. This process was followed by resin impregnation, which was divided into two stages: (1) fabrication of the layer of untreated kenaf where it was impregnated into 1, 2, 3, and 4 layers to make an untreated kenaf unsaturated polyester composites as a control composite; and (2) fabrication of the $\mathrm{ZnO}$ NP-treated kenaf where the resin was impregnated into 1, 2, 3, and 4 layers of kenaf to make a $\mathrm{ZnO}$ NP-treated kenaf unsaturated polyester composite. Next, the composites were compressed for $10 \mathrm{~min}$ without heating. The prepared composite was measured and cut to $2.5 \mathrm{~cm} \times 20 \mathrm{~cm}$. The authors compared the untreated kenaf unsaturated polyester composite at room temperature with the $\mathrm{ZnO} \mathrm{NP}$-treated kenaf unsaturated polyester composite. The weathering study was performed in accordance to the ASTM D1435-13 (2013) standard. The specimens were prepared and exposed to weather for 6 months in intervals of 2 weeks and after each interval, the samples were tested. Finally, the physical characterization was conducted with a scanning electron microscope (JSM6400; JEOL Ltd., Tokyo, Japan) and mechanical testing for the tensile and flexural tests were performed in the Kubang Gajah Laboratory, Universiti Malaysia Perlis, via a universal testing machine (Instron 5569; Instron, Norwood, MA, USA) based on ASTM D638-14 (2014).

\section{RESULTS AND DISCUSSION}

\section{Imaging and X-ray Analysis}

Figure 1 illustrates the results of the SEM investigation of $\mathrm{ZnO}$ NPs distribution. The $\mathrm{ZnO}$ NPs showed uniform distribution. The average zinc oxide nanoparticle diameter and length were approximately between $25 \mathrm{~nm}$ to $50 \mathrm{~nm}$ and $100 \mathrm{~nm}$ to $200 \mathrm{~nm}$, respectively.

Figure 2 shows the typical peaks of the zinc nanoparticles, and it confirmed that the ZnO NPs had a nanosized, crystallized, pure well, hexagonal wurtzite structure that ranged from $30 \mathrm{~nm}$ to $35 \mathrm{~nm}$. Based on the results, the average size distribution of the $\mathrm{ZnO}$ NPs was $30 \mathrm{~nm}$. 


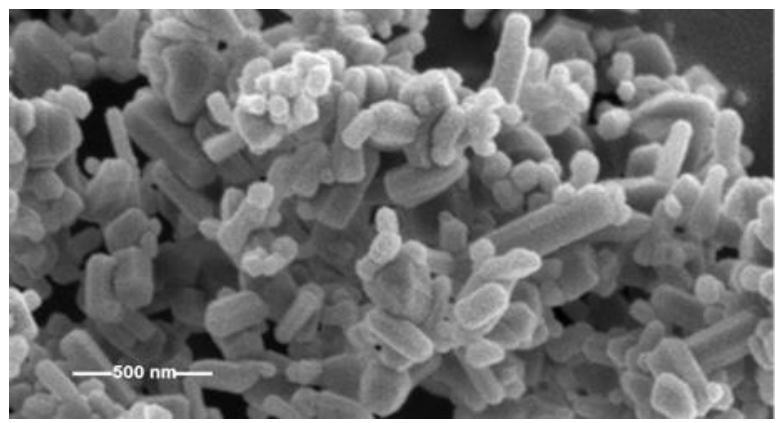

(a)

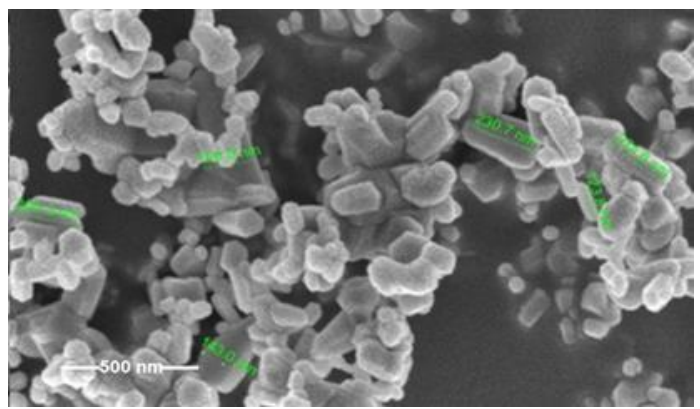

(b)

Fig. 1. Scanning electron microscope (SEM) image of ZnO NPs: (a) with no radial measurement and (b) with radial measurement

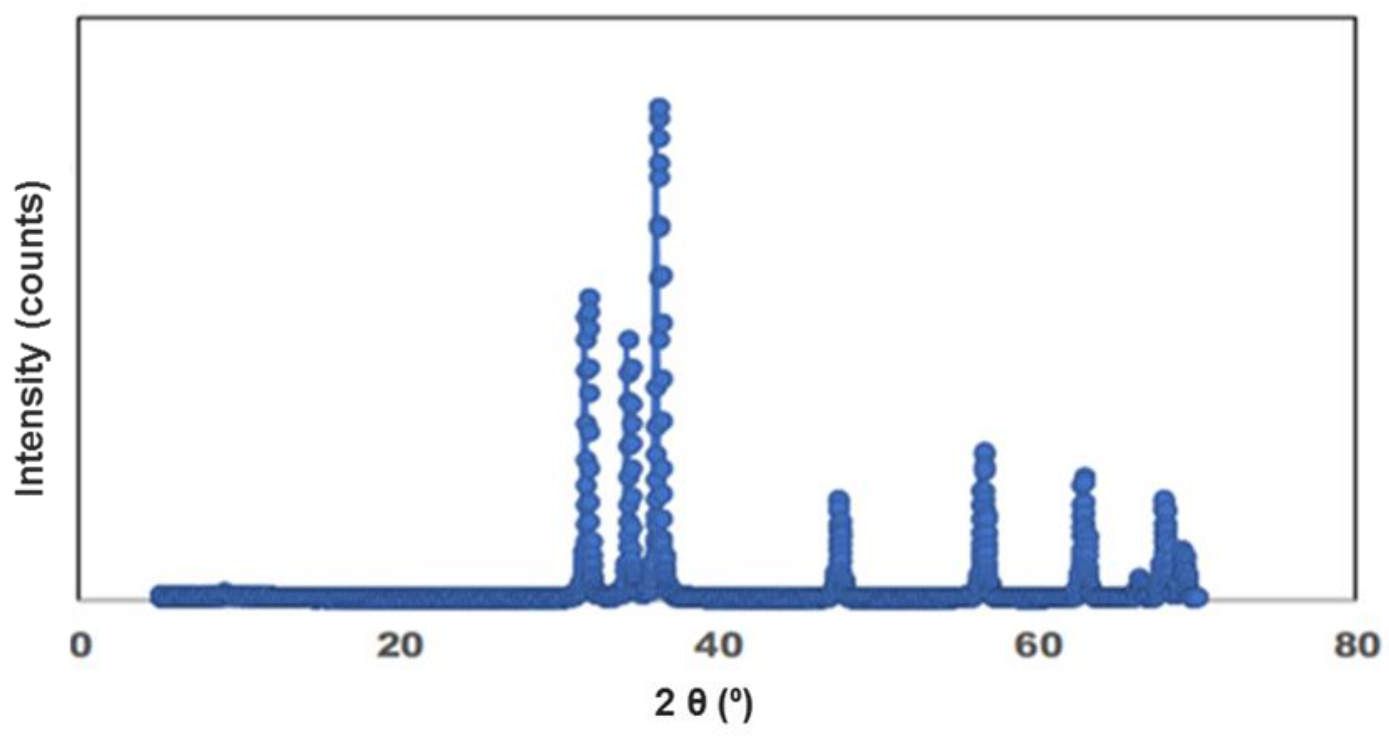

Fig. 2. XRD pattern of $\mathrm{ZnO} N P s$

Figure 3 shows the presence of the $\mathrm{ZnO}$ NPs in the kenaf fibre and the zinc nanoparticle dispersion on the kenaf within the polymer matrix. The composite was prepared and polished to reveal their interior nanostructures. The figure indicated the SEM monograph of the view of the cross-sectional area of the nanoparticle dispersed specimens at 5 different concentrations, 1\%, 2\%, 3\%, 4\%, and 5\%. As shown, the nanoparticles were uniform and well dispersed. However, the concentration distribution was different for the extremely high concentrations, such as $4 \%$ and $5 \%$, and showed less uniform distribution compared to the lower concentrations, i.e. $1 \%$ and $2 \%$. The higher concentrations showed gaps due to the formation of voids caused as a result of poor adhesion between the nanoparticles and the polymer matrix. However, the composites that contained the lower concentrations showed more uniformly dispersed nanoparticles, which indicated that the nanoparticle surface treatment with a lower concentration improved the nanoparticle dispersion in the polymer matrix due to a uniform intermolecular force distribution. The appearance of a uniform distribution indicated an improved chemical interaction between the nanoparticles and the kenaf. Thus, the particle surface treatment caused the particle to disperse. 




Untreated kenaf fibre

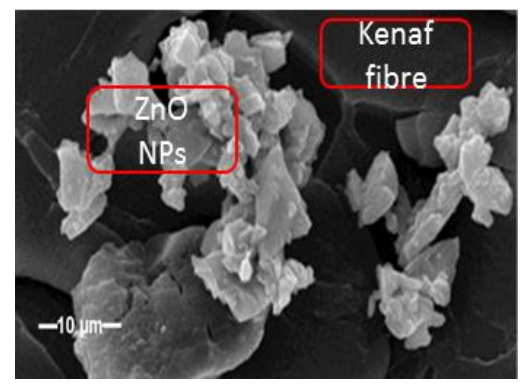

$3 \%$ treated kenaf fibre
$1 \%$ treated kenaf fibre

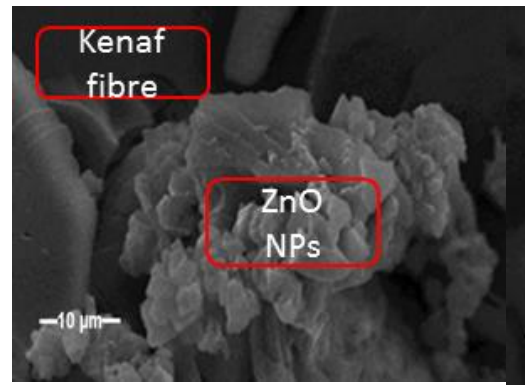

$4 \%$ treated kenaf fibre

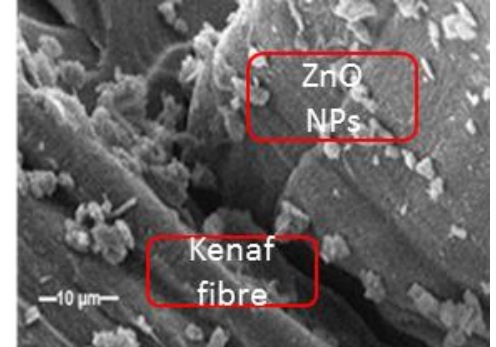

$2 \%$ treated kenaf fibre

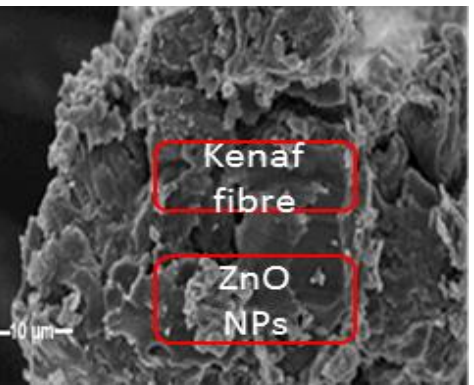

$5 \%$ treated kenaf fibre

Fig. 3. SEM image of different concentrations of treated and untreated kenaf fibres

Figure 4 shows the flexural results of the fabricated $\mathrm{ZnO}$ NPs-treated kenaf polymer composite. This was found to provide weather resistance based on solar radiation assisted moisture repellent.

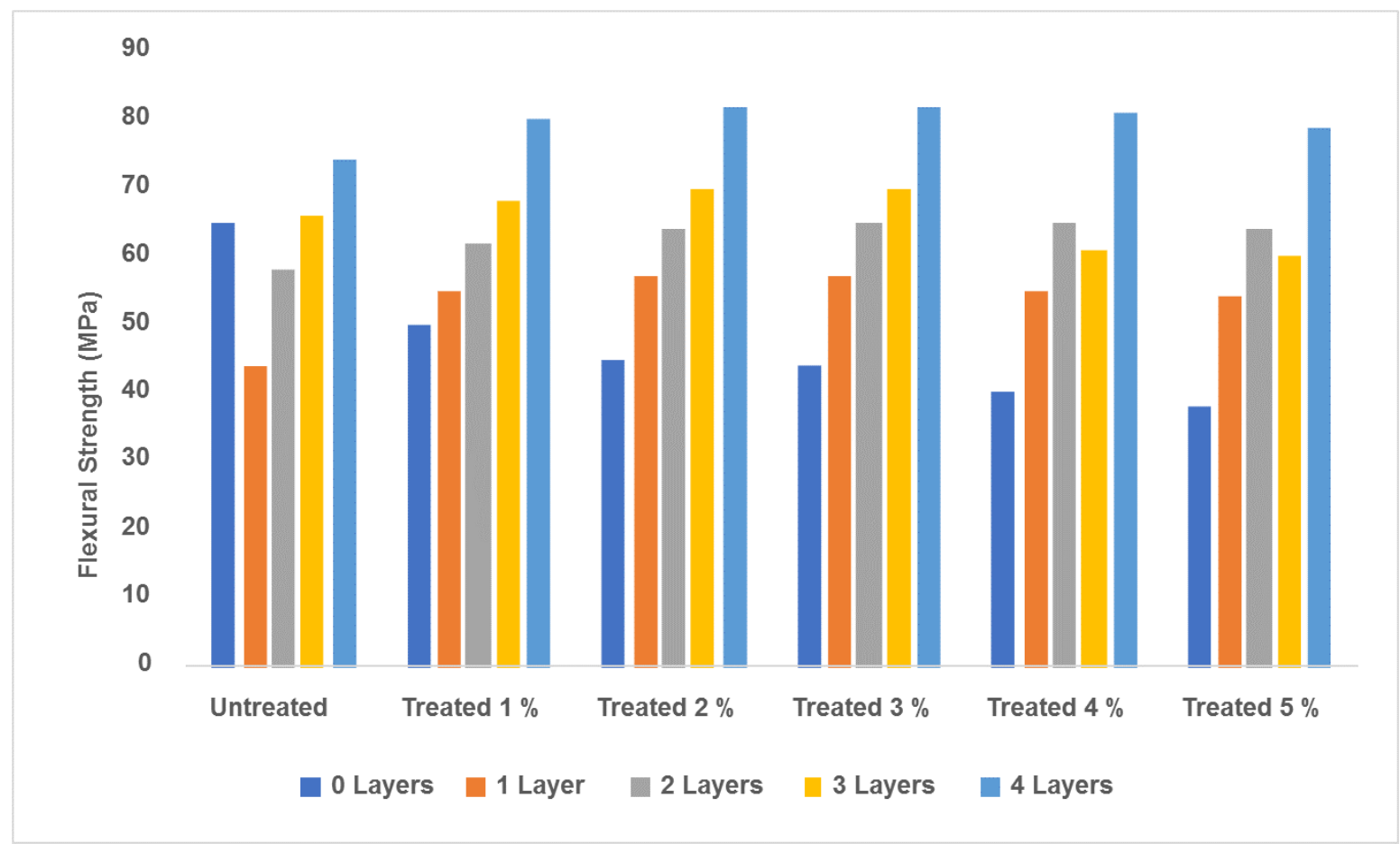

Fig. 4. Flexural results of the fabricated ZnO NPs-treated and untreated kenaf polymer composite 
Prior to the exposure to outdoor weathering, the composite was characterised using mechanical and physical analytical tools to reveal the effects of the $\mathrm{ZnO} \mathrm{NP}$ concentration, and the flexural strength performance was tested against 5 different concentrations: $1 \%, 2 \%, 3 \%, 4 \%$, and $5 \%$. The effect of the different concentrations of $\mathrm{ZnO}$ NPs on the flexural strength of the natural fibre polymer composite is shown in Fig. 3 , where the flexural strengths are shown for systems containing various concentrations and non-treated 1\%, 2\%, 3\%, 4\%, and 5\% (w/w) ZnONPs. It was clearly evident that the untreated polyester (zero kenaf) was affected by the presence of the ZnO NPs. Initially with zero $\mathrm{ZnO}$ NPs it showed approximately a $65 \times 10^{-6} \mathrm{~Pa}$ flexural strength, and it gradually decreased with an increase in concentration: $50 \times 10^{-6} \mathrm{~Pa}, 43 \times 10^{-6} \mathrm{~Pa}, 41 \times 10^{-}$ ${ }^{6} \mathrm{~Pa}, 39 \times 10^{-6} \mathrm{~Pa}, 37 \times 10^{-6} \mathrm{~Pa}$ for $1 \%, 2 \%, 3 \%, 4 \%$, and $5 \%(\mathrm{w} / \mathrm{w}) \mathrm{ZnO} \mathrm{NPs}$, respectively. This was largely due the ZnO NPs interference with the interfacial molecular chain of the polymer matrix. However, this reduction was immediately countered by the increase in the kenaf layers that reinforced the composite. The first layer provided $43 \times 10^{-6} \mathrm{~Pa}, 45 \times 10^{-6} \mathrm{~Pa}, 52 \times 10^{-6} \mathrm{~Pa}, 50 \times 10^{-6} \mathrm{~Pa}, 49 \times 10^{-6} \mathrm{~Pa}$ for $1 \%, 2 \%$, $3 \%, 4 \%$, and $5 \%(\mathrm{w} / \mathrm{w})$, respectively. However, one very interesting discovery was noted, when the concentration increased above $2 \%$, the flexural strength tended to gradually decrease, this is because as loading of the nanoparticles in the polymer matrix increases, the amount of the particles increases which causes more interaction between the particles themselves rather than with matrix. This will then bring agglomeration and form lumps which eventually affect the entire composite by creating a void.

The results of the study suggested the addition of $\mathrm{ZnO}$ NPs to a polyester/kenaf composite influenced the mechanical properties that modify the mechanical properties of the processed materials and application, such as the flexural strength and the tensile strength of the material. The nanoparticles treatment had a strong effect on the mechanical and subsequent physical properties of the composites. Prior to weathering, the treatment on the kenaf was based on 5 different concentrations, $1 \%, 2 \%, 3 \%, 4 \%$, and $5 \%$. For the composite fabrication shown, $2 \%$ had a strong effect on the overall composite's mechanical properties. The mechanical analysis showed an increased flexural strength stability and break elongation in the functionalized $\mathrm{ZnO}$ NP-treated kenaf polyester resin composites. The polymer nanocomposites with $2 \% \mathrm{ZnO} \mathrm{NP}$ had the most stable mechanical properties with moderate elastic properties compared with those systems containing $1 \%, 3 \%, 4 \%$, and $5 \%$ concentrations of $\mathrm{ZnO}$ NPs. The mechanical properties of the composites that contained different layers of kenaf mat demonstrated a positive influence on the polymer nanocomposites mechanical properties. The material increased in stiffness with an increase in the number of layers from 1 to 5 layers. The results of the weathering confirmed the stability of the polymer nanocomposites with increased stability. Among the influential concentrations seen through the experiments, $1 \%$ and $2 \%$ showed the most promise. The $2 \% \mathrm{ZnO}$ NPs with 5 layers of kenaf layers revealed no remarkable change in the mechanical degradation through a 6 month weathering period. The results of the mechanical properties tests suggested that a $2 \%$ $\mathrm{ZnO}$ NP concentration with 5 kenaf layers had the highest moisture resistance, where the $\mathrm{ZnO}$ NPs acted as a water repellent agent in this composite.

Figure 5 presents the effects of various $\mathrm{ZnO} \mathrm{NP}$ concentrations and kenaf layers on the break elongation of the composites. The concentrations of the untreated and treated $1 \%, 2 \%, 3 \%, 4 \%$, and $5 \%(\mathrm{w} / \mathrm{w}) \mathrm{ZnO}$ NPs and with 1, 2, 3, or 4 kenaf layers were prepared. As expected, the break elongation of these composites generally decreased with increased amounts of $\mathrm{ZnO} \mathrm{NP}$ and kenaf layers. This suggested that the presence of the 
kenaf fibres and $\mathrm{ZnO}$ NPs increased the stiffness of the composite and does not contribute to the elasticity or the final composite flexibility as equally observed by Tawakkal et al. (2014) in their study. Zero kenaf layers initially showed a $4.5 \%$ elongation in an untreated composite and gradually decreased from $4.5 \%$ to $4.2 \%, 3.8 \%$, $3.3 \%$, and $2.8 \%$ for 1 layer, 2 layers, 3 layers, and 4 layers, respectively. This was due to an ability to withstand the load transfer from the matrix, however, with a low reinforcing effect. In contrast, a similar trend was seen in the $1 \%$ treated composite, with an initial elongation of $4 \%$, and gradually decreased from $4 \%$ to $3.9 \%, 3.6 \%, 3 \%$, and $2.7 \%$ for 1 layer, 2 layers, 3 layers, and 4 layers, respectively; as well as for the $2 \%$ treated composite, with an initial elongation of $3.9 \%$, and gradually decreased from $3.9 \%$ to $3.6 \%, 3 \%$ and $2.7 \%$ for 1 layer, 2 layers, 3 layers and 4 layers, respectively, until a 5\% decrease was shown. The observed decrease in flexibility of the composites was likely due to stiffness of the composites and due to a deficiency in adhesion as a result of foreign molecule interfaces in the matrix, which gradually led to a weak load transfer from the matrix to the fibres.

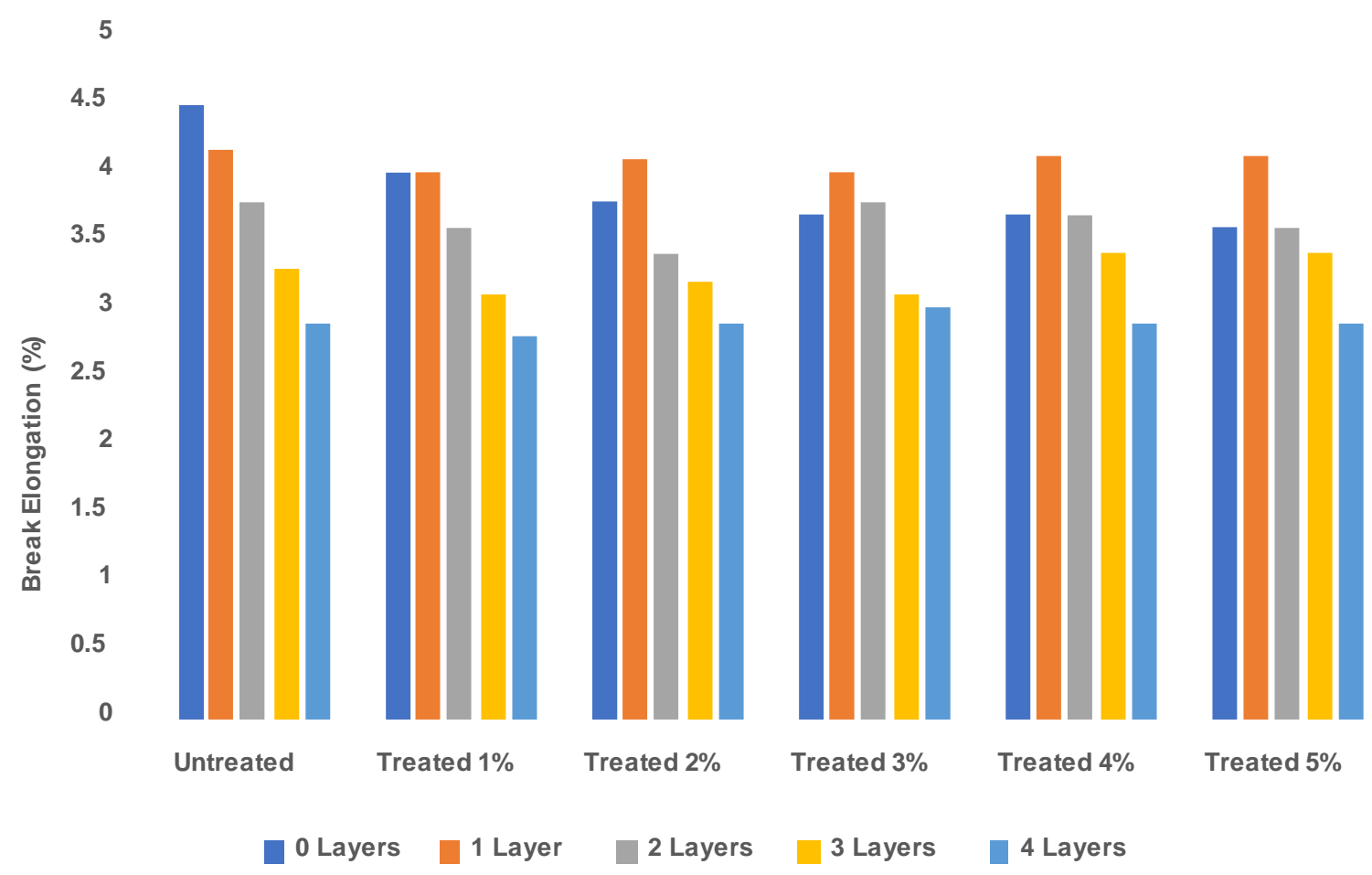

Fig. 5. Effect of various ZnO NP concentrations and kenaf layers on the break elongation of the composites

Figure 6 represents the tensile strength of the untreated composite, 1\%, 2\%, 3\%, $4 \%$, and 5\% ZnO NPs-treated composite with the corresponding 0 layers, 1 layer, 2 layers, 3 layers, and 4 layers of kenaf mat. The untreated composite showed some higher tensile strength compared to the ZnO NPs-treated composite. This was attributed to the fact that the $\mathrm{ZnO} \mathrm{NP}$ addition entered into the fibril orientations of the kenaf, as well as the kenaf polymer interface. This interference subsequently moderately improved the mechanical properties. The tensile strength of the untreated composite was $29 \times 10^{-} 6 \mathrm{~Pa}$, the $1 \%$ treated was $27 \times 10^{-6} \mathrm{~Pa}$, the $2 \%$ treated was $26.5 \times 10^{-6} \mathrm{~Pa}$, the $3 \%$ treated was 26 $\times 10^{-6} \mathrm{~Pa}$, the $4 \%$ treated was $25 \times 10^{-6} \mathrm{~Pa}$, and the $5 \%$ treated was $26.5 \times 10^{-6} \mathrm{~Pa}$ with a 
linear decrease in tensile strength, which made this an important attribute due to its effect on the biodegradability of the composite. Moreover, apart from the ZnO NPs effect on the composite, the layers of the kenaf equally improve the stiffness of the composite. From Fig. 6, it was shown that the layers of the kenaf had a noticeable effect.

60

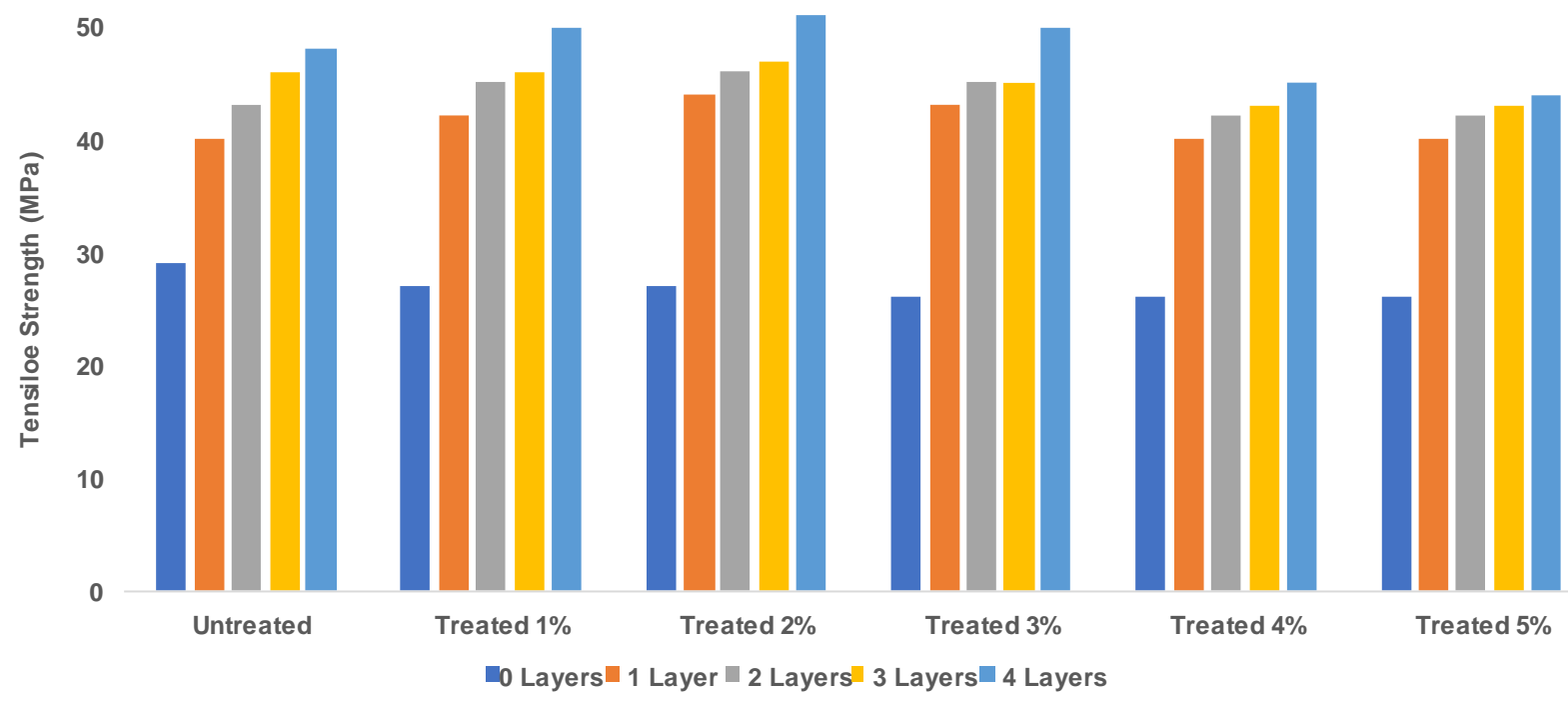

Fig. 6. The tensile strength of the composite with varying ZnO NP concentration and kenaf layers

The addition of a layer increased the tensile strength from $29 \times 10^{-6} \mathrm{~Pa}$ to $39 \times 10^{-6} \mathrm{~Pa}$, almost a $50 \%$ increase in tensile strength in nontreated composites. Likewise, a treatment of $1 \%$ with no kenaf layers was $27 \times 10^{-6} \mathrm{~Pa}$, and was improved with one layer to a tensile strength of $42 \times 10^{-6} \mathrm{~Pa}$. The 2 kenaf layers with a $1 \%$ treatment had a tensile strength of $44 \times 10^{-6} \mathrm{~Pa}, 3$ kenaf layers with a $1 \%$ treatment had a tensile strength of $47 \times 10^{-6} \mathrm{~Pa}$, and 4 kenaf layers with a $1 \%$ treatment had a tensile strength of $50 \times 10^{-6} \mathrm{~Pa}$. It very interesting to note the as the concentration of the $\mathrm{ZnO}$ NPs increased beyond $2 \%$, the tensile strength tended to decrease. This is attributed to the higher concentration encouraged conglomeration of the nanoparticles, which affected the molecular bonding interfacial forces. 


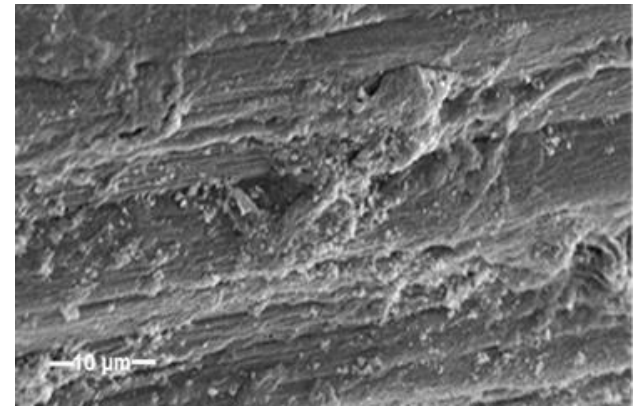

1. Single kenaf layer

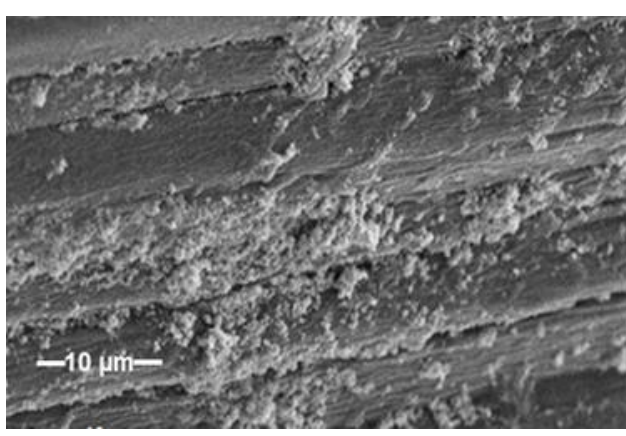

3. 3 Kenaf layers

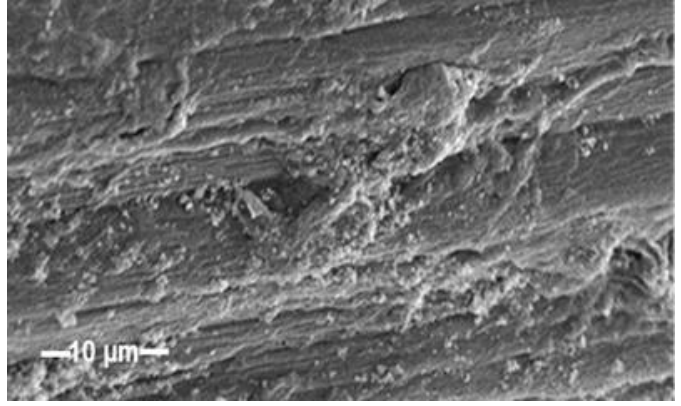

2. 2 Kenaf layers

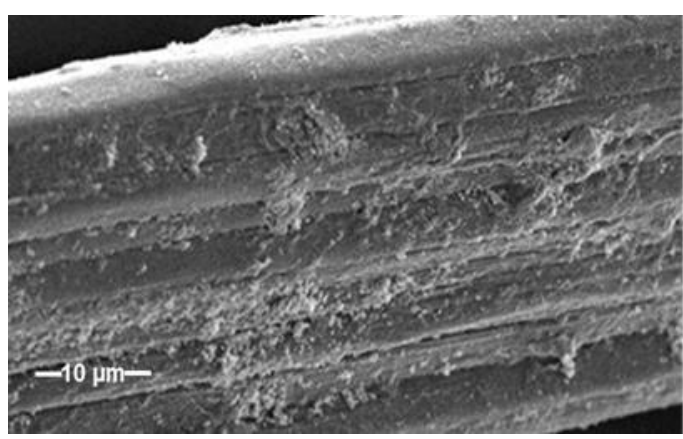

4. 4 Kenaf layers

Fig. 7. The kenaf arrangement for different numbers of layers (1 to 4 )



1. 1 Month

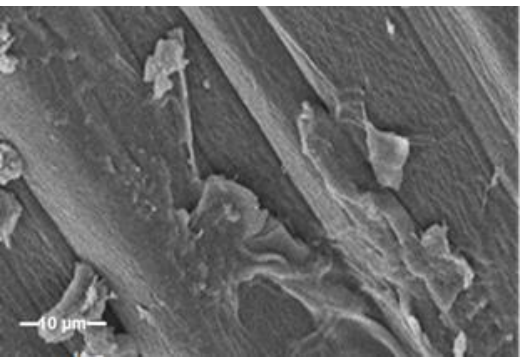

2. 2 Months

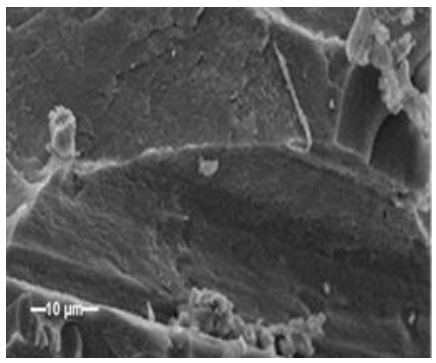

3. 3 Months

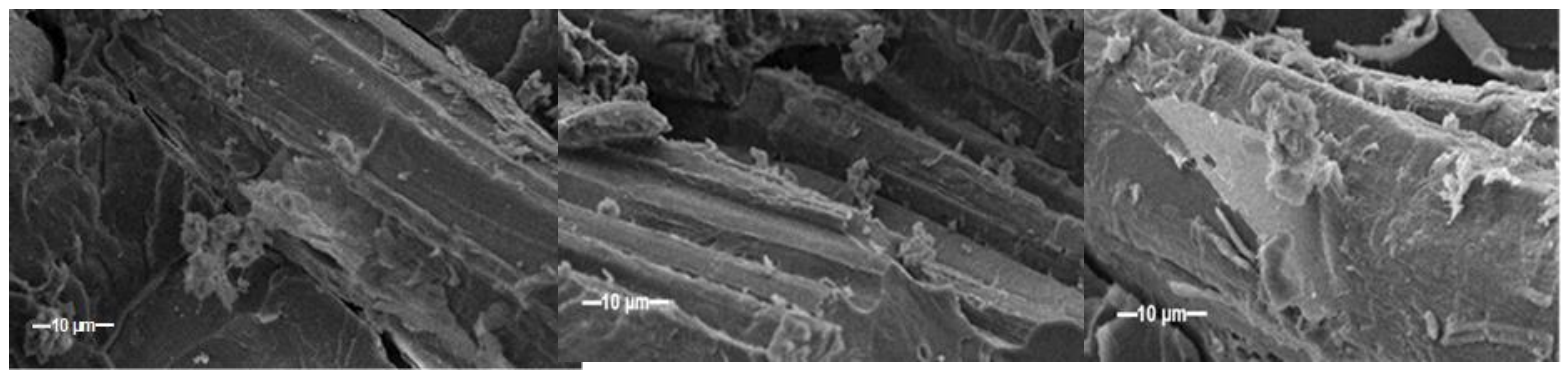

4. 4 Months

5. 5 Months

6. 6 Months

Fig. 8. SEM micrographs of the physical appearance of the composite with exposure time 
Figure 8 shows the SEM micrograph of the physical appearance of the composites after 1 month of exposure until 6 months had passed. The composites tended to gradually accumulate surface fractures at different weathering periods. The composites for a 1 month period showed copolymer lining with long straight laid fibres. As the exposure increased from 1 month to 6 six months, the surface fractures increased in size. However, the general physical condition remained good and the degree the fibre length was pulled out decreased. This was possibly due to the ability of the $\mathrm{ZnO}$ NPs to dissociate $\mathrm{H}_{2} \mathrm{O}$ on the surface of the composites because of the photon activities and the results of the observed radiation from the sun and other sources that the fibres were well adhered to the polymer via the ZnO NPs.

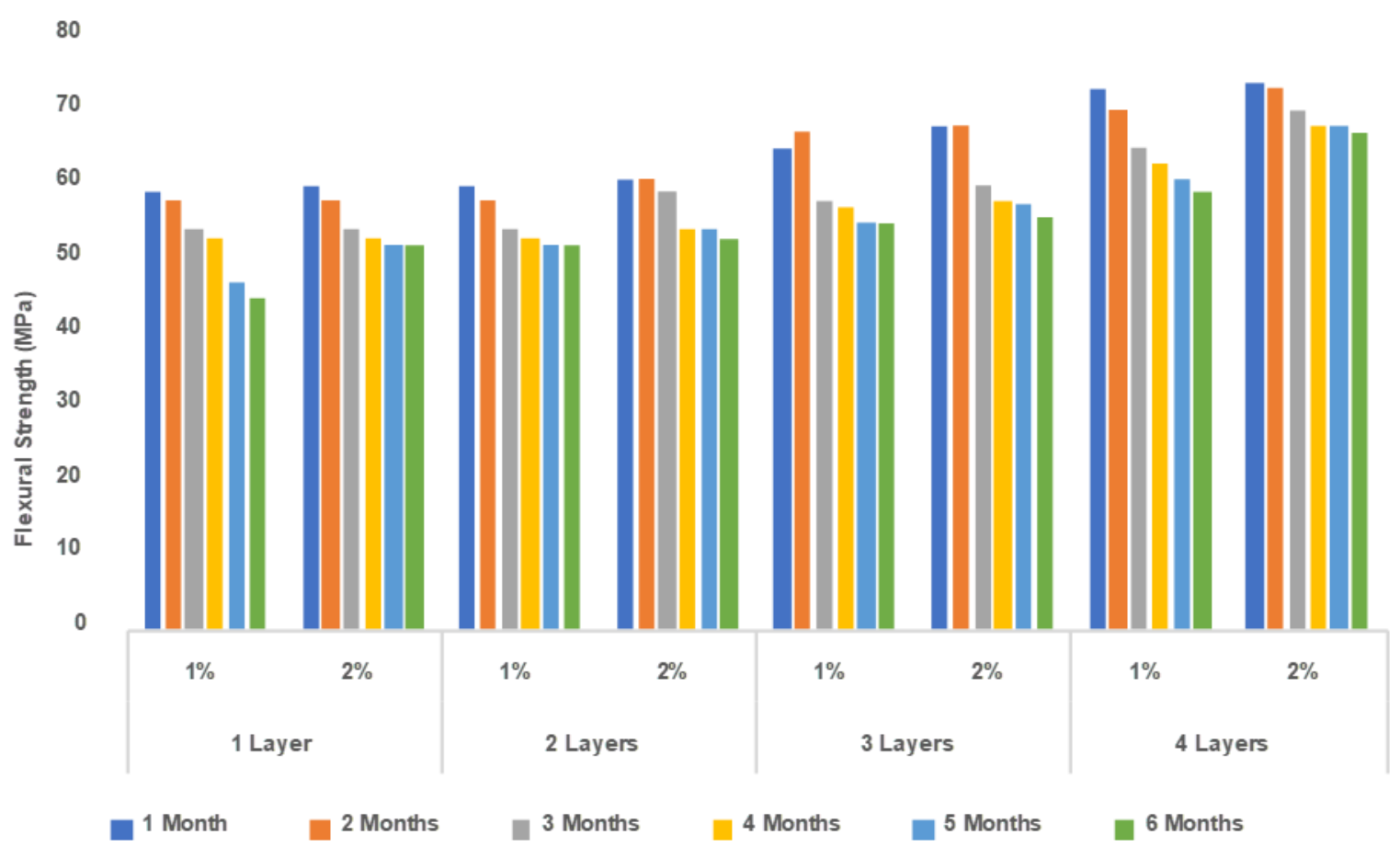

Fig. 9. Effect of weathering periods on the ZnO NP-treated kenaf polymer composites

Figure 9 shows the flexural strength of the composite under different weather periods, with different layers and concentrations of the ZnO NPs. Some interesting trends were observed, with a single kenaf layer and $1 \%$ concentration, at the initial weathering period, the flexural strength was $60.1 \times 10^{6} \mathrm{~Pa}$, gradually reduced to $58.1 \times 10^{6} \mathrm{~Pa}$ in the second month, and at the sixth month of weathering, the flexural strength was reduced to $44.5 \times 10^{6} \mathrm{~Pa}$. The $2 \%$ treated single layer of kenaf showed an improvement over the treatment. At the initial treatment periods, the flexural strength was $60.1 \times 10^{6} \mathrm{~Pa}$ like that of the $1 \%$ treatment results. However, as the treatment concentration increased, the rate of increased flexural strength was minimal compared to the $1 \%$ treatment. This was attributed to the $2 \%$ treatment providing a better interfacial affinity between the polymer and the kenaf. Moreover, the $2 \%$ treatment for the 4 kenaf layers, showed very interesting trends, at the third month of the treatment, no further reduction in flexural strength was seen. Hence, this provided a mechanically stable composite. Therefore, the authors can suggest that, a $2 \%$ treatment with 4 kenaf layers provided better stability against wear and tear due to weather conditions. In contrast, the $\mathrm{ZnO}$ NPs had a greater effect in providing 
water resistance than the polymer composite. It served as a photocatalysis, which absorbed the radiation from the sun and converted it to heat that in turn repelled the moisture content from the composites. The photocatalysis mechanism based on the radiation from the sun is stated as follows. The ZnO NPs $(E g=3.37 \mathrm{eV})$ were under light radiation from the sun and were capable of trapping considerable amounts of radiation with little reflection. According to (Halliwelland and Gutteridge 1984), the absorption energized the electron in the balanced band and the electron transition from the valence band to the conduction band resulted in the creation of an electron-hole pair in which the electron $\left(\mathrm{e}^{-}\right)$was reductive, and the hole $\left(\mathrm{h}^{+}\right)$was oxidative. The hole $(\mathrm{H}+)$ reacted with the $\mathrm{OH}^{-}$on the surface of the $\mathrm{ZnO} \mathrm{NPs}$, and generated hydroxyl radicals $\left(\mathrm{OH}^{-}\right)$, superoxide anion $\left(\mathrm{O}_{2}^{-}\right)$, and perhydroxyl radicals $\left(\mathrm{HO}_{2}^{-}\right)$. The breaking of the peroxide into these ions released energy, due to the formation of the water molecule, because the excessive energy released in this process increased the temperature at the surface of the composite, and thus increased the water repellence. This will create UV protective cover, in turn producing an invisible protection layer with highly hydrophobic properties. In this case when water contacts the $\mathrm{ZnO}$-treated surface of the composite, its rolls off without penetrating (Sasani et al. 2017).

Table 2. Comparison of the Flexural and Tensile Properties of the Best Sample (For $2 \%$ ZnO NPs with 4 layers)

\begin{tabular}{|l|l|l|l|l|l|l|l|}
\hline $\begin{array}{l}\text { Properties } \\
\text { For }(2 \% 4 \\
\text { layers) }\end{array}$ & $\begin{array}{l}\text { Before } \\
\text { exposure }\end{array}$ & $\begin{array}{l}\text { After } \\
\text { exposure:1 } \\
\text { months }\end{array}$ & $\begin{array}{l}\text { After } \\
\text { exposure:2 } \\
\text { months }\end{array}$ & $\begin{array}{l}\text { After } \\
\text { exposure:3 } \\
\text { months }\end{array}$ & $\begin{array}{l}\text { After } \\
\text { exposure:4 } \\
\text { months }\end{array}$ & $\begin{array}{l}\text { After } \\
\text { exposure:5 } \\
\text { months }\end{array}$ & $\begin{array}{l}\text { After } \\
\text { exposure:6 } \\
\text { months }\end{array}$ \\
\hline $\begin{array}{l}\text { Flexural } \\
\text { strength } \\
\text { (MPa) }\end{array}$ & 78.5 & 74.3 & 73 & 70 & 68.7 & 66.9 & 66.1 \\
\hline $\begin{array}{l}\text { Tensile } \\
\text { strength } \\
\text { (MPa) }\end{array}$ & 57.2 & 55.2 & 52.2 & 45.8 & 40.0 & 40.0 & 39.8 \\
\hline
\end{tabular}

Table 2 compares the flexural and tensile properties of the best sample ( $2 \% \mathrm{ZnO}$ NPs with 4 layers). The flexural strength decreased by $4.2 \%, 5.5 \%, 8.5 \%, 9.8 \%, 11.6 \%$ and $12.4 \%$ for $1,2,3,4,5$, and 6 months, respectively. In the early stages of the exposure, it reduces in the rate of decrease. This can be attributed to the stability provided by the ZnO NPs. The tensile results show a similar trend. This indicates that the fibre treatment improved the tensile and flexural strength stability. However, a study was conducted by (Faseha et al. 2014) on the treatment of kenaf with 3\%, 6\% and 9\% $\mathrm{NaOH}$ solution. Their results showed that the treatment decreased the compatibility between the polymer matrix and kenaf fiber, resulting in significant reduction of the mechanical properties of polymer composites. 


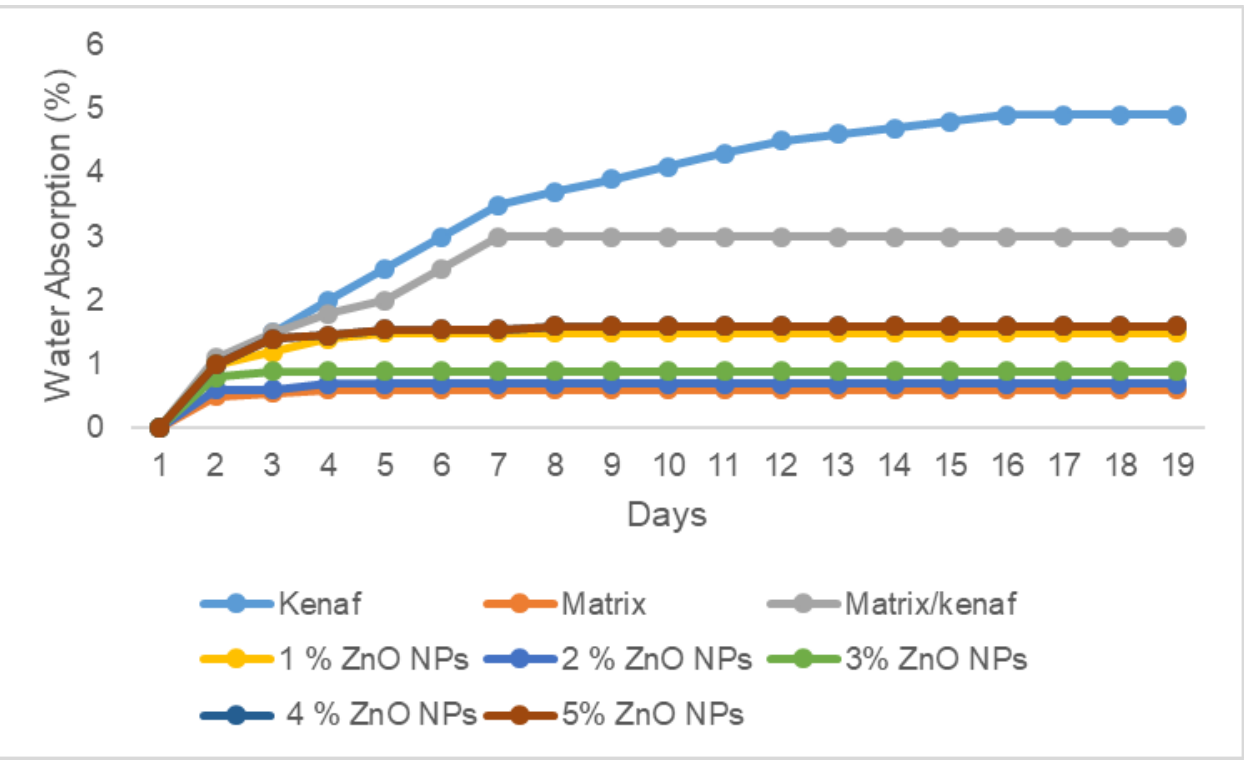

Fig. 10. Water uptake study of untreated and kenaf ZnO NPs treated composites

The water uptake of untreated pure kenaf, kenaf composites untreated and kenaf composites treated with 1\%, 2\%, 3\%, 4\%, and 5\% ZnO NPs. It can be seen from Fig. 10 that the untreated pure kenaf and kenaf composites had the highest water uptake. The specimens of untreated pure kenaf, kenaf/matrix composites untreated, the water uptake was high. The water uptake increased sharply, indicating the rapid water penetration into the composite materials. However, after 12 to 13 days, the water uptake was slow, indicating that the tendency is less to absorb water as it was reaching the equilibrium state. Moreover, the absorption for the treated samples showed an interesting trend. The rate of water uptake was only high in the first three days of exposure. This was attributed to the ability of the ZnO NPs to provide UV blocking activity, making surface protective with more of hydrophobic. The difference in equilibrium time and water uptake can be attributed to the effect of treatment of kenaf with ZnO NPs, as the tendency toward water uptake was significantly decreased in comparison to that of untreated fibers at the same concentration. This was equally observed in the flexural strength and tensile strength.

\section{CONCLUSIONS}

The fabrication and characterization of the $\mathrm{ZnO}$ NP-treated kenaf polymer composites for weather resistance based on solar radiation assisted moisture repellent was successfully performed and characterised in terms of physical and mechanical properties.

1. The addition of $\mathrm{ZnO}$ NPs to a polyester/kenaf composite influenced the mechanical properties that modified the mechanical properties of the processed materials and application, as well as the flexural strength and tensile strength of the material allowing the highest with the 4 layer kenaf mat with $73 \mathrm{MPa}(2 \%)$ and $52 \mathrm{MPa}(2 \%$ $\mathrm{ZnO}$ NP), respectively. This indicated that the nanoparticle treatment had a noticeable effect on the mechanical and subsequent physical properties of the composites at moderate treatment concentration. 
2. The mechanical analysis showed an increased flexural strength stability and elongation at break in the functionalized $\mathrm{ZnO}$ NP-treated kenaf polyester resin composites with a decreased elongation at break from $4.5 \%$ to $2.5 \%$ for 4 layers $(2 \%$ $\mathrm{ZnO} \mathrm{NP).}$

3. The mechanical properties of the composites containing different layers of kenaf mat demonstrated influence on the polymer nanocomposites and the results of the weathering confirmed the stability of the polymer nanocomposites with increased stability with the treatment concentration of the 4 layer kenaf ( $2 \% \mathrm{ZnO} \mathrm{NP})$. That formulation maintained the stability with no degradation after the first 3 months, showing a stable $73 \mathrm{MPa}$ for the remaining exposure periods.

\section{ACKNOWLEDGMENTS}

The authors acknowledge Lembaga Kenafdan Tembakau Negara (LKTN) and Universiti Malaysia Perlis (UniMAP) for providing facilities and for their support.

\section{REFERENCES CITED}

Alavudeen, A., Rajini, N., Karthikeyan, S., Thiruchitrambalam, M., and Venkateshwaren, N. (2015). "Mechanical properties of banana/kenaf fibre-reinforced hybrid polyester composites: Effect of woven fabric and random orientation," Materials \& Design 66(Part A), 246-257. DOI: 10.1016/j.matdes.2014.10.067

Al-Oqla, F. M., and Sapuan, S. M. (2014). "Natural fiber reinforced polymer composites in industrial applications: Feasibility of date palm fibers for sustainable automotive industry," Journal of Cleaner Production 66, 347-354. DOI: 10.1016/j.jclepro.2013.10.050

Arrakhiz, F. Z., El-Achaby, M., Malha, M., Bensalah, M. O., Fassi-Fehri, O., Bouhfid, R., Benmoussa, K., and Qaiss, A. (2013a). "Mechanical and thermal properties of natural fibers reinforced polymer composites: Doum/low density polyethylene," Materials \& Design 43, 200-205. DOI: 10.1016/j.matdes.2012.06.056

Arrakhiz, F. Z., Malha, M., Bouhfid, R., Benmoussa, K., and Qaiss, A. (2013b). "Tensile, flexural and torsional properties of chemically treated alfa, coir and bagasse reinforced polypropylene," Composites Part B: Engineering 47, 35-41 DOI: 10.1016/j.compositesb.2012.10.046

ASTM D638-14 (2014). "Standard test method for tensile properties of plastics," ASTM International, West Conshohocken, PA.

ASTM D1435-13 (2013). "Standard practice for outdoor weathering of plastics," ASTM International, West Conshohocken, PA.

Bakar, N. A., Chee, C., Y., Abdullah, L. C., Ratnam, C. T., and Ibrahim, N. A. (2015). "Thermal and dynamic mechanical properties of grafted kenaf filled poly (vinyl chloride)/ethylene vinyl acetate composites," Materials \& Design 65, 204-211. DOI: 10.1016/j.matdes.2014.09.027

Cierech, M., Wojnarowicz, J., Szmigiel, D., Bączkowski, B., Grudniak, A. M., Wolska K. I., Łojkowski, W., and Mierzwińska-Nastalska, E. (2016). "Preparation and 
characterization of ZnO-PMMA resin nanocomposites for denture bases," Acta of Bioengineering and Biomechanics 18(2), 31-41. DOI: 10.5277/ABB-00232-2014-04

Deka, H., Misra, M., and Mohanty, A. (2013). "Renewable resource based "all green composites" from kenaf biofiber and poly(furfuryl alcohol) bioresin," Industrial Crops and Products 41, 94-101. DOI: 10.1016/j.indcrop.2012.03.037

El-Sabbagh, A. (2014). "Effect of coupling agent on natural fibre in natural fibre/polypropylene composites on mechanical and thermal behaviour," Composites Part B: Engineering 57, 126-135. DOI: 10.1016/j.compositesb.2013.09.047

Faseha, S,. Azman, H., Mohammed, S., I, Munirah, M., Mahbub, H., (2014). "Effect of ammonium polyphosphate on flame retardancy, thermal stability and mechanical properties of alkali treated kenaf fiber filled PLA biocomposites," Materials and Design 54, 425-429. DOI: 10.1016/j.matdes.2013.07.095

Faseha,S., Azman, H.. Mohammed, S., I., Munirah, M., Mahbub, H., (2014). "Effect of ammonium polyphosphate on flame retardancy, thermal stability and mechanical properties of alkali treated kenaf fiber filled PLA biocomposites," Materials and Design 54, 425-429. DOI: 10.1016/j.matdes.2013.07.095

Zhanhu, G., Kenny, L., Yutong, L., Ho W., N., Sergy P., and Hahn, H. T. (2008). "Fabrication and characterization of iron oxide nanoparticles reinforced vinyl-ester resin nanocomposites," Composites Science and Technology 68(6), 1513-1520. DOI: 10.1016/j.compscitech.2007.10.018

Halliwell, B., and Gutteridge, J. M. C. (1984). "Oxygen toxicity, oxygen radicals, transition metals and disease,” Biochemical Journal 219(1), 1-14. DOI: 10.1042/bj2190001

Kabir, M. M., Wang, H., Lau, K. T., and Cardona, F. (2013). "Effects of chemical treatments on hemp fibre structure," Applied Surface Science 276, 13-23. DOI: 10.1016/j.apsusc.2013.02.086

Karger-Kocsis, J., Mahmood, H., and Pegoretti, A. (2015). "Recent advances in fiber/matrix interphase engineering for polymer composites," Progress in Materials Science 73, 1-43. DOI: 10.1016/j.pmatsci.2015.02.003

Lai, S.-M., Kao, Y.-H., Liu, Y.-K., and Chiu, F.-C. (2016). "Preparation and properties of luffa fiber- and kenaf fiber-filled poly(butylene succinate-co-lactate)/starch blendbased biocomposites," Polymer Testing 50, 191-199. DOI: 10.1016/j.polymertesting.2016.01.015

Mohammed, M., Rozyanty, A. R., Osman, A. F., Adam, T., Hashim, U., Mohammed, A. M., Noriman, N. Z., Dahham, O. S., and Betar, B. O. (2017a). "The weathering effect in natural environment on kenaf bast filled unsaturated polyester composite and integration of nano zinc particle for water repellent," Micro and Nanosystems 9(1), 16-27. DOI: 10.2174/1876402909666170531075138

Mohammed, M., Rozyanty, A. R., Adam, T., and Betar, B. O. (2017b). “ZnO characterization, UV and photocatalysis mechanism for water repellent phenomena in polymer poly composite," in: AIP Conference Proceedings 1885, Article ID 020215. DOI: $10.1063 / 1.5002409$

Reddy, K. O., Maheswari, C. U., Shukla, M., Song, J. I., and Rajulu, A. V. (2013). "Tensile and structural characterization of alkali treated Borassus fruit fine fibers," Composites Part B: Engineering 44(1), 433-438. DOI: 10.1016/j.compositesb.2012.04.075

Salleh, F. M., Hassan, A., Yahaya, R., and Azzahari, A. D. (2014). "Effects of extrusion temperature on the rheological, dynamic mechanical and tensile properties of kenaf 
fiber/HDPE composites," Composites Part B: Engineering 58, 259-266. DOI: 10.1016/j.compositesb.2013.10.068

Sasani, Ghamsari, M., Alamdari, S., Han W., and Park, H. H. (2017). "Impact of nanostructured thin $\mathrm{ZnO}$ film in ultraviolet protection," International Journal of Nanomedicine 28(12), 207-216. DOI: 10.2147/IJN.S118637

Shah, D. U. (2014). "Natural fibre composites: Comprehensive Ashby-type materials selection charts," Materials \& Design 62, 21-31. DOI: 10.1016/j.matdes.2014.05.002

Shukor, F., Hassan, A., Islam, M. S., Mokhtar, M. M., and Hassan, M. (2014). "Effect of ammonium polyphosphate on flame retardancy, thermal stability and mechanical properties of alkali treated kenaf fiber filled PLA biocomposites," Materials \& Design 54, 425-429. DOI: 10.1016/j.matdes.2013.07.095

Tawakkal, I. S. M. A., Cran, M. J., and Bigger, S. W. (2014). "Effect of kenaf fibre loading and thymol concentration on the mechanical and thermal properties of PLA/kenaf/thymol composites," Industrial Crops and Products 61, 74-83. DOI: 10.1016/j.indcrop.2014.06.032

Xia, C., Zhang, S., Shi, S. Q., Cai, L., and Huang, J. (2016). "Property enhancement of kenaf fiber reinforced composites by in situ aluminium hydroxide impregnation," Industrial Crops and Products 79, 131-136. DOI: 10.1016/j.indcrop.2015.11.037

Yang, B., Nar, M., Visi, D. K., Allen, M., Ayre, B., Webber III, C. L., Lu, H., and D'Souza, N. A. (2014). "Effects of chemical versus enzymatic processing of kenaf fibers on poly(hydroxybutyrate-co-valerate)/poly (butylene adipate -co-terephthalate) composite properties," Composites Part B: Engineering 56, 926-933 DOI: 10.1016/j.compositesb.2013.09.022

Yusoff, R. B., Takagi, H., and Nakagaito, A. N. (2016). "Tensile and flexural properties of polylactic acid-based hybrid green composites reinforced by kenaf, bamboo and coir fibers," Industrial Crops and Products 94, 562-573. DOI: 10.1016/j.indcrop.2016.09.017

Venkateshwaran, N., Perumal, A. E., and Arunsundaranayagam, D. (2013). "Fiber surface treatment and its effect on mechanical and visco-elastic behaviour of banana/epoxy composite," Materials \& Design 47, 151-159. DOI: 10.1016/j.matdes.2012.12.001

Zaikikhani, P., Zahari, R., Sultan, M. T. H., and Majid, D. L. (2014). "Extraction and preparation of bamboo fibre-reinforced composites," Materials \& Design 63, 820828. DOI: 10.1016/j.matdes.2014.06.058

Article submitted: January 10, 2018; Peer review completed: March 25, 2018; Revisions accepted: June 11, 2018; Published: July 11, 2018.

DOI: 10.15376/biores.13.3.6480-6496 